\title{
Discussion on the Perfection of Law about the Security of Labor Interests for Doctors
}

\author{
Jie Zhang \\ Law and Public Management School, Leshan Normal University, 614000 Leshan Sichuan, China
}

\begin{abstract}
The doctor is a typical laborer that mainly provides the medical technical service and that is unable to be directly protected by labor laws due to systems and other reasons. And their labor value cannot be comprehensively realized by its provided labor service, so that the labor interests of doctor fail to receive the security from laws. This article tries to find out the reasons behind the scenes through the analysis on the current situation of labor interests security for doctor, and refer to the mature legislation experience in foreign countries according to the national conditions of China to perfect the laws and regulations so as to enable the doctor that cure the people to have rewards of labors and get respect and security from the labor interests.
\end{abstract}

Keywords. labor interests of doctor; labor value; income allocation method; legal security

In the group of labors, the doctor belongs to a special group, and their profession is a complex combination of mental and physical labors. While, due to the lack and defect of national administrative system and medical system, the doctor, as a laborer, stands outside the protection of national labor labor laws, and their labor interests cannot be comprehensively secured by national laws, which makes the high-risk and low-security doctor confused and embarrassed, as well as seriously questions the national legal system. This article makes analysis on the current situation of labor interests for doctor to analyze the reasons of the dilemma, and refers to the legal system of labor interests security for doctor in various countries in different systems, which has a significant impact and actual meaning on the methods of establishing a perfect legal security system of labor interests for doctor in the new situation.

\section{Analysis on current situation: dilemma of labor interests security for doctor}

The doctor is a profession that mainly provides medical technical service, and it is a labor costs considerable mental efforts for clinical doctor, especially for surgeons. There's no doubt that the doctor belongs to laborer, as well as the producer of medical service and the creator of service goods value. ${ }^{[1]}$ While, due to the lack of national human resources system and medical system, the labor interests for doctor in China cannot be secured comprehensively and reliably.

\subsection{Inconsistency of doctor's current income and their provided labor value}

The Wealth of the Nation written by economist Adam Smith 200 years ago said that: "We hand our life over to a doctor..... The trust like this shall be peacefully entrusted to those people, and the reward they receive shall be consistent with the social status required for this kind of trust. Plus, the long-term education and considerable costs they previously undertook shall enable them to have a higher price of labor." In fact, the doctors in most of the countries belong to a high-income class. The salary of doctors in Japan, HK, Brazil and the US is twice or four times higher than that of public servant. The famous remark about the doctor from Adam Smith had long been globally practiced. What about the income of Chinese doctor? According to on-line investigation report from DXY Investigation: from 2012 to 2013, the average yearly income for Chinese doctor was 67,516 yuan. $75 \%$ of the doctors have the annual salary lower than 40,000 yuan, as well as their income, but what about their provided labors? It is displayed in the questionnaire conducted in 19 hospitals in 8 cities, such as Beijing, Shanghai and Guangzhou, that among 2,183 doctors participating in this investigation, almost $80 \%$ work for $8-12$ hours, $67 \%$ used to work continuously for over 36 hours, $80 \%$ do not drink water in their work, and $60 \%$ are on leave for less than 3 days even in the golden week. [2] Compared to other professions, the labor value of doctor even belongs to high strength and low value. The registration fee of outpatient service for one doctor who is even the expert, is averagely less than 10 yuan. The labors with high strength for doctor contrast unfavorably with the low 
income, and the current income system for doctor does not actually reflect the labor value of a doctor.

\subsection{As a laborer, the doctor is not included in the protection of labor laws}

The labor laws are to adjust the labor relation, and the labor laws and labor contract laws are the minimum legal security formulated based on the basic human rights of laborers, so they shall be applicable to all the laborers in the territory of a country. In view of the current laws in China, the doctor is definitely a laborer, but they cannot comprehensively enjoy the protection of labor laws and labor contract laws. The main reasons that induce the current situation consist in the limitation of traditional theoretical conception and current administrative system. The hospital is not for profits or a main body of market economy. The working time and range for a doctor is specified and the labor value or labors cannot be calculated by working hours. This kind of labor relation is much different from that between employer and employee, which shall be adjusted and formulated [3]by special laws. In such case that the traditional theory is not supported by special laws, the doctor, as a laborer, falls into a dilemma that they cannot protect their own labor interests by labor laws.

\subsection{The working time and vacation system are not reliably secured by any laws}

As for the minimum labor time, neither the national medical laws and regulations nor the regulations in the hospital specifies the "minimum labor time", and most of the doctors work for over 60 hours in a week. As for the vacation system, generally the shift system is implemented other than fixed vacation in Saturday or Sunday of every week due to the particularity of the doctor work. The annual sabbatical leave for a doctor is short, namely 7-10 days per capita in one year. As specified by labor laws, the overtime worker enjoys the salary compensation system, while the laws and regulations and the internal regulations of medical institution do not have any salary compensation system for overtime working, weekend or overtime working in legal holidays. The current legal blank makes the doctors work in a overload condition without any security of their health, and condition of labor reproduction cannot be realized. The overtime working in the holidays is not remedied by any corresponding salary compensation, so the labors provided by doctors is not in proportion to the income.

\section{Discover the source: reasons that in- duce the lack of labor interests security for doctor}

It is found from the inspection of current situation of labor interests security for doctor in China that, the concentration level in the labor interests security for doctor is far behind other countries and regions, either in medical or judiciary field. There are many reasons that induce this current situation. In general, it is reflected mainly in the following aspects.

\subsection{The complex labor method of doctor is hard to be calculated or measured by formula.}

The labor of a doctor cannot be calculated by amount or pieces just as that in production enterprises. The scholars try to research the labor composition of doctors, among which W.C. Hsiao (1992) proposes an RBRVS method which had a most representative definition for doctor's labor. By discussion and analysis, it finally assumed the doctor's labor is composed of 1. Duration of service; 2 . Mental labor and judgment; 3. Professional skills and physical labor; 4. Psychological pressure. ${ }^{[4]}$ This method determined the objective payment level of each clinical department by calculating the training costs, working intensity, service time and its relative service costs of each clinical department, as well as comparing them with non-medical industries. Due to the low threshold of entrance and graduation appraisal, there are so many Chinese doctors with varied levels, and the medical service price is determined by administrative department of medical . Even the bonus is distributed according to qualifications but not calculated by actual labors. So currently, RBRVS medical is hard to be implemented in China.

\subsection{The nature of medical institution and em- ployment system confuse the basic rights which shall be enjoyed by doctors as laborers.}

The hospital belongs to public institution, a social organization not for profits but with the nature of public interests, so the labor of a doctor cannot be measured by salary income. According to the current situation of personnel preparation system of national institutions, there are two relations between the doctor and human resources, prepared doctor and unprepared doctor. The status of prepared doctor is the same as national public servant, and its salary is sourced from the governmental financial expenses. Their income level is determined by the government, so the income status cannot be determined by the market according to their provided labors. Even the unprepared doctor, namely the contractual doctor, is in employment relation with the hospital. As a laborer, they can protect their legal interests by applicable labor laws and labor contract laws. But due to the particularity of the work in medical industry and the limitation of Chinese medical system, the vacation and salary compensation system are often not applicable to the contractual doctor.

\subsection{In the national sense, the respect and protec- tion of professional identity of doctors is not formed.}

The medicine features service for others, and a qualified doctor shall also requires a solid professional skills, which may be partly clarify that why the doctor profession shall be respected. As for a society, the profession of a doctor is holy. They are the guardians of health and life for people. The doctor is always the preferentially re- 
quired objective, either in wars or peaceful era. In such case, the doctor shall be the first to be respected and protected by the whole society and national citizens. Due to the defect in education and appraisal system, as well as the imperfection of mechanism system, the Chinese doctors are in a tensioning relation with their patients. And the status of a doctor is not respected by the whole country and people. Furthermore, the protection measures for living health and labor interests of doctors are far more backward.

\subsection{The government's price control for doctor's labor prevents the comprehensive reflection of labor value of doctors}

The medical system cares for the realization of health rights and health fairness for people, so in consideration of ethics, the governments from many countries in the world carry out various interference or price control over the various service prices of medical system. China is not an exception. The government controls the labor price of doctors, including medical charges and multiple service fees related to labors. This kind of control prevents the medical care of doctors and other labors from realizing its own values through normal charging, so that they will otherwise compensate for the economic loss by some abnormal methods, such as increasing the use of medicines and medical appliances, kickbacks of medicine and receiving red package. This will not only intensify the contradiction between doctor and patient, destroy the good professional image of a doctor, but also prevent the formation of an efficient incentive that the doctor may provide the best medical knowledge favorable for patient after they get the large amount of compensation by selling the medical knowledge.

\section{Reference and perfection: the labor interests security for doctor shall only be realized by laws.}

\subsection{Newly released employment system for pub- lic institution makes the doctor possible to be- come the laborer protected by labor laws.}

In Jul. 1, 2014, Regulation on the Personnel Management of Public Institutions was officially put into force, by which the public institution gave up the lifetime system and changed to contract employment system. The new employment system defines the relation between the doctor and hospital as a labor contract relation. Then the medical department shall formulate relevant regulations, refer to relevant legislation experience in foreign countries and formulate a sanitary compensation system of vacation and overtime system applicable for Chinese doctors according to the actual conditions of China. According to the current situation of Chinese medical system, the weekly working time for a doctor shall not be over 60 hours, and there shall be 10 hours rest after the shift. If a doctor performs medical work overtime or when they shall rest, it shall obtain the consent from the very doctor who may also enjoy the salary compensation for overtime working. Currently, the paid leave specified by Chinese hospital for doctor is generally short, about 10 days in a year, which is much insufficient for doctors that have high risk and large pressure. For example, the doctors in Australia have less than 10 days of paid sick leave and 5 weeks of paid leave annually, so the doctors in Chinese hospital shall enjoy at least 20 days of paid leave annually, which is also consistent with Chinese current situation.

\subsection{Focus on the non-economic salary treatment of doctor, and secure it by laws}

Compared to some foreign countries, the range of noneconomic salary enjoyed by Chinese doctors are too small. The Chinese doctors do not enjoy more welfare or treatment in their living and study subsidies, insurance types and taxation. The basic reason consists in the insufficient understanding and respect from the government, nation and ordinaries about the value and status of doctors that provide medical service for people. Therefore, we shall improve the non-economic salary of doctors to make them enjoy a wider range of social welfare and preferential policies. In terms of personal income tax and deduction policy, we shall help the doctor purchase the health and accident insurance, as well as confirm and protect the welfare and preferential treatment of housing subsidies, further education, etc. by legal means such as local regulations. All the above contents must be the high recognition of the professional technical labor and risk undertaking of doctors, and will secure the labor interests of doctors in a more comprehensive manner.

\subsection{The laws allow the doctors for multi-sited practice to increase the sharing of medical data and increase the doctor's income.}

In the medical field of various countries in the world, the laws from America, Britain, Germany and Australia allow the doctors for multi-sited practice. Most of the American doctors belong to freelancers, and Australia also allows the part-time doctors to do more part-time jobs outside the fixed working time. Generally, a doctor may do the practice in 3-4 hospitals at the same time. Determination enacted by Chinese 18th Third Plenary Session proposed that "Doctors are allowable for multisited practice". While it is still of no obvious effect due to several reasons. The legislator shall amend the Practicing Physicians Law of the People's Republic of China and add the regulations in the laws that the qualified doctors have the right for multi-sited practice. The detailed conditions may be specified by National People's Congress in local regulations. In drafting the conditions of multi-sited practice for doctors, the titles, period of actual operation, moral standards and other aspects about a doctor shall be considered. In conferring the multi-sited practice right for doctor, we may also pay attention to the reasonable definition of the division of medical accident responsibility, time and frequency of multi-sited practice, etc. for multisited practice doctors, so as to avoid the responsibility evasion due to the occurrence of medical accident. 


\subsection{The government shall increase the financial expense in the salary income of doctors to in- crease their salary income level.}

As for national financial expenses on the medical cares, the $\mathrm{UN}$ requires that in the developing countries, the governmental financial expenses on the medical industry shall account for $3 \%$ of the GDP in their countries. In China, the national expenses on medical cares had a considerable ratio of increase, $32.5 \%$ more than the previous year, but it only accounted for $1.35 \%$ of the total GDP, lower than that in most of the countries in the world. The severe lack of governmental financial expenses on medical care make the doctors have few basic salary incomes from governmental financial expenses, which did not show any respect about the doctor doing the high-risk and high-strength work. Therefore, one of the key points is to increase the governmental financial expenses, increase the basic salary income for doctors and focus on the labor interests for doctors.

\subsection{Adopt the floating wage system, and deter- mine the income of doctors obtained according to service items by supply and demand relation of market and selection of patient}

If there's no value expression for one that heals other people, the people themselves will have inferior or even no value. Respect for doctor's value is a respect for the value of human himself. We shall implement the marketoriented income allocation system for doctors, determine the labor price of doctors by supply and demand relation of market and determine the service price by patient according to the skills, knowledge, professional judgment, moral standard and other factors of doctors. Only in the above manners will the value of human and doctors be reflected. Adopting the internationally used floating wage system for bonus income other than the fixed salary income may better reflect the actual labor value of doctors. The floating wage system is applicable to the salary income of doctors obtained according to service items, but the charge according to service items shall reflect the technical value and risk costs of doctors and be added with judgment from patients about the labor value of doctors, so as to further decrease the ratio of the items, such as medical appliances inspection, in the charge, and increase the ratio of labor value for human efforts. Only in such way, the medical service price will be returned to normality and the labor interests that shall be enjoyed by the doctors as the laborers are secured indeed.

\section{References}

1. Lian Haian, Guo Yani, Zhen Wenxuan, etc. Reflection of labor value for doctors in the new medical reform situation [J]. Chinese Hospital Management. 2011, (6):6.

2. Jiang Naijun, Yang Lichun \& Liu Jingjing. 2nd Series of Investigation on Living Situation for Chinese Doctors: How tired the doctors will be. [OL] http://www.dxy.cn/bbs/thread/11261320\#11261320. 2008-03-06. Abstracted from Life Times

3. Wu Gaossheng. Why does the adjustment objective of labor laws not include national public servants, doctors and teachers [J]. Working Communication of NPC, 1995, (5):25.

4. Hsiao WC et al. Establishing the estimation of doctor's labor for the purpose of RBRVS [J]. Foreign Medical Sciences Sanitation Economics, 1992, (2):90. 